\title{
STRATEGI PENGEMBANGAN AGROINDUSTRI SERAT SABUT KELAPA BERKARET (SEBUTRET) (Studi Kasus di Kabupaten Sambas)
}

\author{
JUNARDI $^{1)}$, SUKARDI ${ }^{2)}$, YANDRA ARKEMAN ${ }^{2)}$, ANDIYONO $^{1)}$ \\ 1) Program Studi Agroindustri Pangan Politeknik Negeri Sambas \\ ${ }^{2)}$ Program Studi Teknologi Industri Pertanian Institut Pertanian Bogor
}

\begin{abstract}
The combination ofcoconutcoirandrubbercan produce rubberized coir products(sebutret). The sebutret is verypotential to be developedto gain value added and increase farmers and local government incomes. The research objectiveswere to assessinternal and external factorsthat affect theproduct development and the implicationofstrengths, weaknesses, opportunities, and threats. The data obtained were analyzed descriptively and quantitatively in the form of weighted average scores and analysis strategies with SWOT analysis matrix, IFE, EFE and IE. The studyshowsthat the main strength is the availability of sebutret product market and its main weakness is thelow competitiveness, limited scope of local villages and districts. Meanwhile the main opportunity is sebutret manufacturing technology already exists and the main threat is the absence of a strong business partnership. The analysisshows thedevelopment of sebutret agro industry can be managedwith market penetration strategy and product development. Implication of the analysis is formulated alternative strategy, namely: conduct accurate data collection, conduct a feasibility study, produce sebutret accordance with market demand, conduct the preparation of resources, establish processing industries, cooperate with the competent institutions, provide equipment and machinery, provide expert as facilitators, conduct promotion.
\end{abstract}

Keywords: rubberized coir, development strategy, value-added

\section{PENDAHULUAN}

Serat sabut kelapa memiliki potensi untuk dikembangkan menjadi produk-produk yang bernilai komersial (Tejano, 1985). Potensi dari serat sabut kelapa (mattress fibre atau coir fibre) yang merupakan hasil dari pengolahan sabut kelapa sebenarnya dapat digunakan menjadi a) penahan panas pada industri pesawat terbang, b) bahan pengisi jok atau bantalan kursi pada industri mobil, c) bahan geotekstil untuk perbaikan tanah pada bendungan, d) bahan cocosheet sebagai pengganti busa pada industri spring bed, e) bahan untuk membuat berbagai kebutuhan rumah tangga seperti tali atau tambang, sapu, sikat, keset, pot bunga, gantungan bunga, isolator, karpet, gumpalan benang ikat, filter air, dan bahan pewarna batik, f) selain itu kemampuan sabut kelapa ditambah dengan karet daur ulang dapat dimanfaatkan sebagai peredam suara, dan g) meningkatkan stabilitas dan ketahanan struktur jalan apabila digunakan sebagai bahan pencampur dalam pengaspalan (Thulasirajan dan Narasimha, 2011).

Selain dari produk-produk di atas, serat sabut kelapa dapat dikembangkan menjadi produk yang dikenal dengan sebutan serat sabut kelapa berkaret 
(sebutret). Produk ini merupakan kombinasi antara serat sabut kelapa dengan karet alam. Produk serat sabut kelapa berkaret (sebutret) ini sangat berpotensi untuk dikembangkan, terutama untuk bahan baku pembuatan kasur. Simon George (2006) mengatakan bahwa kasur yang berasal dari serat sabut kelapa berkaret merupakan sebuah evolusi dari kasur tradisional yang berasal atau terbuat dari kapas. Selain itu, produk sebutret dapat dikembangkan untuk pembuatan jok, kursi, tas laptop, kopiah, bantal dan guling pada industri furnitur. Selain menciptakan nilai tambah, serat sabut kelapa berkaret mempunyai beberapa keunggulan jika dibandingkan dengan produk serupa yang berbahan baku busa sintetis. Adapun keunggulan dari produk serat sabut kelapa berkaret ini adalah relatif lebih ringan, bersifat lebih sejuk dan dingin, lebih tahan terhadap bakteri, lebih sedikit menampung debu, tidak berisik karena mampu meredam bunyi, mempunyai elastisitas atau kepegasan yang baik, dan kerapatan atau densitasnya dapat divariasi karena bentuknya dapat disesuaikan dengan kemauan konsumen, lebih ramah terhadap lingkungan dan kesehatan (Sinurat, 2003, Maspanger et al, 2005 dan Pujiastuti, 2007).

Untuk mengembangkan agroindustri sebutret diperlukan ketersediaan sumber bahan baku dari tanaman kelapa dan karet. Kedua komoditas tersebut merupakan komoditas unggulan di Kabupaten Sambas, dengan jumlah produksi masing-masing sebesar 14.888 ton/tahun dan 20.192 ton/tahun, sehingga sebutret sangat berpotensi untuk dikembangkan untuk agroindustri yang dapat menopang perekonomian masyarakat dan meningkatkan pendapatan pemerintah daerah. Komoditas kelapa dan karet ini tersebar di 19 Kecamatan di Kabupaten Sambas. Sebagian besar hasil produksi dari komoditas tersebut masih belum dapat menciptakan nilai tambah yang lebih besar, karena kelapa hanya dimanfaatkan untuk pembuatan minyak kelapa, dan sabutnya dianggap limbah yang dibuang, sedangkan karet hanya dijual dalam bentuk bokar (bahan olahan karet) sehingga daya tawar petani sangat rendah.

Berdasarkan gambaran di atas sangat penting untuk dilakukan suatu upaya untuk meningkatkan pendapatan petani dari komoditas kelapa dan karet. Selain itu kegiatan pengembangan ini diharapkan dapat menciptakan agroindustri yang berdaya saing bagi produk domestik. Oleh karena itu, diperlukan suatu perumusan strategi pengembangan agroindustri serat sabut kelapa berkaret di Kabupaten Sambas. Adapun yang menjadi tujuan dari penelitian ini adalah merumuskan suatu strategi pengembangan agroindustri serat sabut kelapa berkaret di Kabupaten Sambas. Secara rinci tujuan-tujuan tersebut adalah sebagai berikut: (1) Mengkaji faktor internal dan eksternal yang berpengaruh, dan implikasi dari kekuatan, kelemahan, peluang dan ancamannya terhadap pengembangan agroindustri pengolahan serat sabut kelapa berkaret di Kabupaten Sambas.(2) Merumuskan strategi pengembangan agroindustri pengolahan serat sabut kelapa berkaret.

\section{METODE PENELITIAN}

Dalam proses penyusunan perencanaan strategi pengembangan agroidustri serat sabut kelapa berkaret dilakukan melalui tiga tahap, yaitu tahap pengumpulandata, tahap analisis dan tahap perumusan strategi. Data yang diambil adalah data sekunder dan data primer. Data sekunder didapat dari penelusuran berupa dokumen dari instansi yang terkait, internet dan sumber pustaka-pustaka 
lainnya yang relevan dengan tofik penelitian. Data primer diperoleh dengan melakukan, wawancara dan penyebaran kuesioner kepada responden. Target responden meliputi petani karet, petani kelapa, pedagang pengumpul karet, pedagang pengumpul buah kelapa, dan masyarakat umum yang akan menjadi calon konsumen dari produk sebutret.Lokasi penelitian dilakukan di Kecamatan yang paling tinggi produksi karet dan kelapa, seperti Kecamatan yang menjadi lokasi dalam penelitian ini adalah Kecamtan Teluk sebagai penghasil karet dan Kecamatan Jawai sebagai daerah penghasil kelapa terbesar di Kabupaten Sambas. Adapun rinciannya adalah sebanyak 70 responden dengan rincian 20 responden daripetani karet, 20 responden dari petani kelapa, 5 responden dari pedagangpengumpul karet, 5 responden dari pedagang pengumpul kelapa, 20 respondendari masyarakat umum. Serta 5 orang responden yang dianggap ahli dalam melakukan penilaian terhadap strategi pengembangan sebutret. Rincian responden ahli adalah seperti Dinas Kehutanan dan Perkebunan 1 orang, Dinas Koperasi, Usaha Mikro, Kecil,Menengah, Perindustrian dan Perdagangan 1 orang, dan Badan PerencanaanPembangunan Daerah 1 orang, serta dari kalangan akademisi 2 orang.

Data yang diperoleh akandikelompokkan untuk menentukan faktor-faktor yang menjadi kekuatan(Strengths), Kelemahan (Weaknesses), Peluang (Opportunities), dan Ancaman(Threats). Setelah itu dirangkum dalam matriks SWOT untuk mengetahui bentuk strateginya. Selanjutnya faktor-faktor tersebut akan dibobot dan dirating dan hasilnya dirangkum dalam matrkis EFE (Eksternal Matrix Evaluation) danmatriks IFE (Internal Matrix Evaluation). Nilai-nilai pada matriks EFE dan IFEdiolah untuk menentukan strategi pengembangan.

\section{HASIL DAN PEMBAHASAN}

\section{A. Identifikasi Faktor Internal (Kekuatan dan Kelemahan)}

Faktor Kekuatannya adalah: 1) Ketersediaan bahan baku yang banyak; 2) Tenaga kerja lokal cukup tersedia; 3) Karet dan kelapa merupakan komoditas andalan masyarakat sebagai sumber pendapatan; 4) Kondisi tanah yang cocok untuk budidaya tanaman karet dan kelapa; 5) Tersedianya pasar produk sebutret.

Sedangkan yang menjadi faktor kelamahannya adalah: 1) Skala usahatani yang dilakukan relatif kecil; 2) Tingkat pendidikan masyarakat masih relatif rendah; 3) Sarana dan prasarana transportasi, listrik dan komunikasi yang kurang mendukung; 4) Penguasaan teknologi oleh petani masih rendah; 5) Belum adanya tenaga ahli atau tenaga profesional tentang proses produksi pembuatan sebutret; 6) Produk masih belum banyak dikenal oleh masyarakat; 7) Kurangnya akses terhadap informasi pasar; 8) Keterbatasan modal; 9) Daya saing yang rendah, hanya sebatas lokal desa dan kecamatan.

\section{B. Identifikasi Faktor Eksternal (Peluang dan Ancaman)}

Faktor Peluangnya adalah: 1) Melalui pengembangan agroindustri serat sabut kelapa berkaret (sebutret) akan dapat meningkatkan pendapatan masyarakat petani (kelapa dan karet), menambah peluang usaha dan lapangan pekerjaan; 2) Masih belum adanya industri pengolahan dan pemanfaatan sabut kelapa; 3) Adanya dukungan yang diberikan oleh Pemda Kabupaten Sambas dalam pengembangan agroindustry; 4) Perekonomian masyarakat yang semakin meningkat; 5) Jumlah penduduk yang semakin meningkat. 
Adapun yang menjadi factor Ancaman adalah: 1) Ketidakpastian harga bahan baku ditingkat petani; 2) Pasar masih dikuasai oleh produk yang berbahan baku dari sintetis; 3) Ekspansi lahan perkebunan kelapa sawit; 4) Pemerintah belum konsisten dalam mengaplikasikan kebijakan tentang pengembangan komoditas unggulan; 5) Politik dan keamanan; 6) Perubahan cuaca; 7) Hama tanaman; 8) Belum adanya kemitraan usaha yang kuat; 9) Kurangnya koordinasi dari instansi yang terkait

\section{Implikasi Faktor Internal dan Eksternal Terhadap Pengembangan Agroindustri Serat Sabut Kelapa Berkaret di Kabupaten Sambas.}

\section{Aspek teknis}

Adapun implikasinya akan berpengaruh terhadap manajemen organsisasi seperti perencanaan, pengendalian, pengelolaan keuangan, pemasaran dan pada proses produksi (rendahnya kreatifitas). Oleh karena itu, untuk meningkatkan pengetahuan baik secara formal maupun non-formal (melalui pelatihan maupun pendampingan) untuk meningkatkan mutu SDM dalam merencanakan dan mengatur proses produksi dan operasi, serta dapat meningkatkan efisiensi biaya produksi, mengurangi tingkat kerusakan pada produk dan dapat meningkatkan mutu produk sebutret melalui inovasi teknologi yang dilakukan, sehingga daya saing produk menjadi lebih tinggi.

2. Aspek non-teknis

Bedirinya industri pengolahan serat sabut kelapa berkaret diharapkan lebih dapat membantu meningkatkan perekonomian masyarakat, karena petani khususnya patani kelapa selain menjual kelapa dalam kopra, juga akan mendapatkan tambahan dari penjualan sabut kelapanya. Oleh karena itu dengan adanya teknologi pengolahan sebutret paling tidak akan dapat membantu masyarakat petani karet dan kelapa dalam upaya untuk meningkatkan nilai tambah pada produk. Tetapi usaha pengembangan industri pengolahan sebutret tidak akan dapat berjalan dengan baik apabila kebijakan yang dibuat oleh Pemerintah Daerah dan perpolitikan yang berkembang kurang mendukung untuk terciptanya usaha tersebut. Oleh karena itu kebijakan-kebijakan yang telah dibuat untuk pengembangan agroinustri harus diaplikasikan dengan sebaik-baiknya, karena menurut Hubeis (2011) kebijakan pemerintah yang berupa undang-undang baik di tingkat pusat, propinsi maupun kabupaten yang akan menentukan beroperasinya suatu perusahaan. Salah satu cara yang dapat dilakukan adalah dengan memfasilitasi dan membangun kemitraan antara UKM-UKM yang ada dengan industri-industri yang lebih besar serta antara industri hulu (pertanian) dengan industri hilir (proses pengolahan). Tanpa adanya keterpaduan tersebut perkembangan usaha agroindustri ini akan sulit untuk dicapai.

\section{Perumusan Strategi Pengembangan Agroindustri Serat Sabut Kelapa Berkaret di Kabupaten Sambas dengan Matriks SWOT}

Alat yang biasa digunakan dalam merumuskan alternatif strategi adalah dengan matriks SWOT. Matriks SWOT ini menghasilkan empat macam kemungkinan alternatif strategi yaitu strategi S-O, strategi W-O, strategi S-T dan strategi W-T sebagai berikut:

1. Strategi S-O; Strategi ini dibuat untuk memanfaatkan semua kekuatan untuk merebut dan memanfaatkan peluang yang ada dengan sebesar-besarnya, yaitu: a) Memanfaatkan teknologi pengolahan sebutret untuk meningkatkan nilai tambah pada komoditas karet dan kelapa. S1,S3,O1,O2,O3,O6; b) 
Memanfaatkan peluang pasar dengan menciptakan produk sebutret yang bervariasi dan bermutu yang disesuaikan dengan selera konsumen. $\mathrm{S} 1, \mathrm{~S} 2, \mathrm{~S} 5, \mathrm{O} 1, \mathrm{O} 2, \mathrm{O} 3, \mathrm{O} 4, \mathrm{O} 5 . \mathrm{O} 6$.

2. Strategi S-T; Strategi ini adalah untuk menggunakan kekuatan yang dimiliki untuk mengatasi ancaman yang ada seperti: a) Meningkatkan konsistensi dalam penerapan kebijakan tentang pembangunan industri khususnya untuk pengembangan agroindustri sebutret. S1,S2,S3,T3,T4,T5,T9; b) Meningkatkan kemitraan antara pemerintah daerah, akademisi, petani dan swasta melalui pengembangan agroindustri sebutret. S1,S3,S5,T1,T2,T5,T8.

3. Strategi W-O; Strategi ini merupakan strategi yang digunakan untuk memanfaatkan peluang yang ada dengan sebesar-besarnya untuk meminimalkan kelamahan-kelamahan yang ada, seperti: a) Mengadakan pelatihan untuk meningkatkan kualitas SDM dalam penyerapan teknologi dan informasi tentang pengolahan dan pasar sebutret. W2,W4,W5,W7,W9,O3,O4.O6; b) Memperkuat pendanaan untuk pengembangan agroindustri sebutret dan peningkatan sarana dan prasarana pendukungnya. $\mathrm{W} 3, \mathrm{~W} 6, \mathrm{~W} 8, \mathrm{O} 1, \mathrm{O} 2, \mathrm{O} 3, \mathrm{O} 6$.

Strategi W - T; Strategi yang digunakan untuk meminimalkan kelamahan dan menghindari ancaman yang ada, antara lain: a) Meningkatkan sosialisai dan promosi tentang teknologi pengolahan maupun hasil produk sebutret. W4,W6,W7,T2; b) Mengadakan kegiatan peremajaan dan perluasan lahan tanaman karet dan kelapa. W1,T3,T4,T5; c) Meningkatan koordinasi antar lembaga yang terkait dalam fungsi dan tata guna lahan khususnya lahan karet dan kelapa serta penanggulangan hama tanaman. W1,T3,T4,T5.T7,T9.

\section{E. Analisis Matriks IFE (Internal Factor Evaluation Matrix)}

Perhitunganfaktor-faktor internal dapat dilihat dalam Tabel 1. Matriks IFE berikut ini:

Tabel 1. Matriks IFE

\begin{tabular}{|c|c|c|c|}
\hline Faktor Internal & Bobot & Rating & Skor \\
\hline \multicolumn{4}{|l|}{ Kekuatan } \\
\hline A. Ketersediaan bahan baku yang banyak. & 0.077 & 4.0 & 0.310 \\
\hline B. Tenaga kerja lokal cukup tersedia. & 0.074 & 3.2 & 0.236 \\
\hline $\begin{array}{l}\text { C. Karet dan kelapa merupakan komoditas andalan } \\
\text { masyarakatsebagai sumber pendapatan. }\end{array}$ & 0.079 & 4.0 & 0.314 \\
\hline $\begin{array}{l}\text { D. Kondisi tanah yang cocok untuk budidaya tanaman karet } \\
\text { dan kelapa. }\end{array}$ & 0.066 & 3.0 & 0.198 \\
\hline E. Tersedianya pasar produk sebutret. & 0.080 & 4,0 & 0.321 \\
\hline \multicolumn{4}{|l|}{ Kelemahan } \\
\hline F. Skala usahatani yang dilakukan relatif kecil. & 0.072 & 2.0 & 0.144 \\
\hline G. Tingkat pendidikan relatif rendah & 0.066 & 2.0 & 0.132 \\
\hline $\begin{array}{l}\text { H. Sarana dan prasarana transportasi, listrik dan } \\
\text { telekomunikasi yang kurang mendukung. }\end{array}$ & 0.069 & 1.6 & 0.111 \\
\hline I. Penguasaan teknologi oleh petani masih rendah. & 0.073 & 1.6 & 0.117 \\
\hline $\begin{array}{l}\text { J. Belum adanya tenaga ahli. tentang proses produksi } \\
\text { pembuatan sebutret. }\end{array}$ & 0.071 & 2.0 & 0.142 \\
\hline K. Produk masih belum dikenal oleh masyarakat. & 0.074 & 1.2 & 0.089 \\
\hline L. Kurangnya akses terhadap informasi pasar & 0.066 & 2.0 & 0.132 \\
\hline M. Keterbatasan modal & 0.060 & 2.0 & 0.121 \\
\hline $\begin{array}{l}\text { N. Daya saing yang rendah, hanya sebatas lokal desa dan } \\
\text { kecamatan. }\end{array}$ & 0.073 & 2,0 & 0.145 \\
\hline Total & 1 & & 2.512 \\
\hline
\end{tabular}




\section{F. Analisis Matriks EFE (External Factor Evaluation Matrix)}

Perhitungan faktor-faktor eksternal dapat dilihat dalam Tabel 2. Matriks EFE berikut ini:

Tabel 2. Matriks EFE

\begin{tabular}{lcrc}
\multicolumn{1}{c}{ Faktor Eksternal } & Bobot & Rating & Skor \\
\hline Peluang & & & \\
A. Meningkatkan pendapatan dan menambah lapangan pekerjaan. & 0.072 & 3.8 & 0.275 \\
B. Masih belum ada industri pengolahan sabut kelapa. & 0.068 & 3.4 & 0.230 \\
C. Adanya dukungan yang diberikan oleh pemda. & 0.066 & 3.0 & 0.199 \\
D. Perekonomian masyarakat yang semakin meningkat. & 0.067 & 3.6 & 0.240 \\
E. Jumlah penduduk yang semakin meningkat. & 0.069 & 3.0 & 0.206 \\
F. Teknologi pembuatan sebutret sudah ada, & 0.071 & 4,0 & 0.286 \\
\hline Ancaman & & & \\
G. Ketidakpastian harga bahan baku ditingkat petani. & 0.064 & 2.0 & 0.128 \\
H. Pasar dikuasai oleh produk yang berbahan baku dari sintetis. & 0.070 & 1.8 & 0.127 \\
I. Pemerintah belum konsisten dalam mengaplikasikan kebijakan. & 0.064 & 1.4 & 0.089 \\
J. Ekspansi lahan perkebunan kelapa sawit. & 0.071 & 1.6 & 0.112 \\
K. Politik dan keamanan. & 0.066 & 1.6 & 0.106 \\
L. Perubahan cuaca. & 0.063 & 1.8 & 0.132 \\
M. Hama tanaman. & 0.056 & 2.0 & 0.112 \\
N. Belum adanya kemitraan usaha yang kuat. & 0.069 & 2,0 & 0.138 \\
O. Kurangnya koordinasi antar instansi yang terkait. & 0.064 & 2.0 & 0.129 \\
\hline Total & 1 & & 2.509 \\
\hline
\end{tabular}

\section{G. Analisis Matriks Internal-Eksternal (Internal-External Matrix)}

Gabungan kedua matriks IFE dan EFE menghasilkan matriks InternalEksternal (IE) yang berisikan Sembilan macam sel yang memperlihatkan kombinasi total nilai tersebut. Nilai IFE yang diperoleh adalah sebesar 2,512 dan nilai EFE adalah 2,509 (Gambar 1. Matrik IE). Perpaduan dari kedua nilai tersebut menunjukan bahwa strategi pengembangan serat sabut kelapa berkaret (sebutret) ini terletak pada sel ke lima, yaitu sel stabilitas yang dapat dikelola dan dilakukan dalam pengembangan kedepannya dengan penetrasi pasar dan pengembangan produk. Menurut David (2009) mengatakan bahwa penetrasi pasar (market penetration) adalah strategi yang mengusahakan peningkatan pangsa pasar untuk produk atau jasa yang ada di pasar saat ini melalui upaya-upaya pemasaran yang lebih besar. Sedangkan pengembanagn produk (product development) menurut David (2009) adalah sebuah strategi yang mengupayakan peningkatan penjualan dengan cara memperbaiki atau memodifikasi produk atau jasa yang ada saat ini.

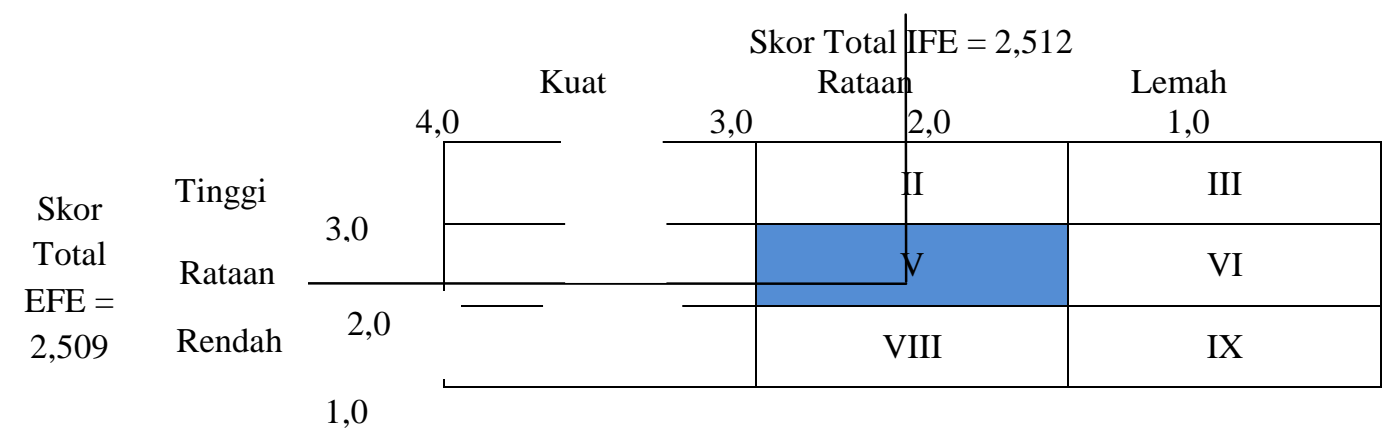

Gambar 1. Matriks IE 


\section{H.Strategi Pengembangan Agroindustri Serat Sabut Kelapa Berkaret.}

Berdasarkan analisis SWOT dan posisi pengembangan agroindustri sebutret di Kabupaten Sambas pada matriks IE (Gambar 2), maka dapat dirumuskan strategi yang dapat dilakukan untuk mengembangkan usaha serat sabut kelapa berkaret, yaitu:

a. Melakukan pendataan ulang yang lebih akurat tentang kepemilikan, fungsi dan tataguna lahan yang ada di kabupaten sambas dengan mengoptimalkan koordinasi antar instansi yang terkait terutama dari Dinas Perkebunan dan Kehutanan, Dinas Pertanian, Badan Pertanahan Nasional, Badan Perencanaan Pembangunan Daerah dan Kecamatan-kecamatan sampai ke desa-desa, agar data yang dimiliki menjadi seragam. Hal ini bertujuan agar lahan-lahan perkebunan karet dan kelapa yang sudah ada dan hutan-hutan yang tersisa tidak beralih fungsi menjadi lahan perkebunan kelapa sawit yang saat ini banyak diminati oleh masyarakat agar ketersediaan bahan baku tetap terjaga. Selain itu juga untuk menghindari adanya kepemilikan ganda dan memperjelas status kepemilikan pada lokasi tanah yang ada.

b. Melakukan studi kelayakan investasi usaha sebutret dengan terperinci agar kedepannya industri yang telah dijalankan tidak mengalami masalah. Oleh karena itu dalam studi tersebut harus memperhatikan beberapa aspek, yaitu aspek pasar (meliputi permintaan, penawaran, harga, program pemasaran dan perkiraan penjualan), aspek teknis dan produksi (meliputi skala produksi, proses produksi, mesin dan fasilitas, perlengkapan, penanganan limbah dan tata letak), aspek keuangan (meliputi sumber pendanaan, biaya, keuntungan dan tingkat pengembalian), aspek manajemen (meliputi struktur organisasi dan tenaga kerja), aspek hukum (meliputibadan hukum, jaminan hukum dan perizinan) dan aspek sosial ekonomi (meliputi devisa negara dan daerah, kesempatan kerja, dampak pada industri lain dan dampak pada masyarakat).

c. Memproduksi sebutret yang sesuai dengan keinginan dan citarasa konsumen. Artinya bahwa sebelum barang-barang yang telah diproduksi dipasarkan, terlebih dahulu dilakukan segmentasi pasar (market segmentation), targeting dan positioning. Segmentasi pasar didefinisikan sebagai pembagian pasar menjadi bagian-bagian konsumen yang berbeda menurut kebutuhan dan kebiasaan belanja mereka. Targeting adalah suatu tindakan memilih satu atau lebih segmen pasar yang akan dimasuki. Sedangkan Positioning adalah penetapan posisi pasar, yang tujuannya adalah untuk membangun dan mengkomunikasikan keunggulan bersaing yang ada di pasar ke dalam benak konsumen (David, 2009), sehingga produk yang telah dihasilkan tepat sasaran. Selain itu, diharapkanproduk yang dihasilkan sesuai dengan perkembangan zaman yang mengedepankan kenyamanan kepada sipemakai produk.

d. Melakukan kegiatan persiapan sumber daya manusia, sumber daya alam, infrastruktur dan sumber pendanaan.

e. Membangun industri pengolahan sebutret yang berbasis kerakyatan dalam rangka meningkatkan kesejahteraan masyarakat dan petani dan peningkatan ekonomi daerah, baik melalui pendirian Koperasi, BUMD, maupun dengan melakukan kerjasama (mitra) dengan pihak swasta.

f. Melakukan kerjasama dengan lembaga-lembaga yang berkompeten dalam bidang pengolahan sebutret seperti dengan Balai peneltian Teknologi Karet 
Bogor (BPTK Bogor) ataupun dengan pengusaha sebutret yang ada di Cilacap dan lain-lain dalam rangka proses alih teknologi.

g. Menyediakan peralatan dan mesin proses produksi untuk menghasilkan produk sebutret.

h. Menyediakan tenaga ahli dibidang pengolahan sebutret dan bisnis agroindustri sebagai tenaga pendamping di lapangan untuk mengadakan kegiatan tindak lanjut (follow-up) secara berkelanjutan terhadap kegiatan pelatihan yang telah dilaksanakan, agar pelatihan tersebut tidak terkesan sia-sia.

i. Melakukan promosi produk sebutret yang dihasilkan, baik di daerah kabupaten sambas itu sendiri, daerah Kabupaten/Kota yang ada disekitarnya sampai pada mancanegara.

\section{KESIMPULAN DAN SARAN \\ Kesimpulan}

1. Faktor yang menjadi kekuatan utama, yaitu tersedianya pasar produk sebutret dengan jumlah nilai sebesar 0,32 , sedangkan faktor kelemahan terbesarnya terletak pada produk masih belum dikenal oleh masyarakat dengan nilai 0,089. Faktor yang menjadi peluang terbesar, adalah teknologi pembuatan sebutret sudah ada dengan nilai 0,286 , sedangkan faktor ancaman terbesarnya terletak pada pemerintah belum konsisten dalam mengaplikasikan kebijakan dengan nilai 0,089. Implikasi secara teknisnya berpengaruh terhadap manajemen organsisasi seperti dalam perencanaan, pengendalian, pengelolaan keuangan, pemasaran dan rendahnya kreatifitas untuk mengembangkan produk. Secara non-teknis berpengaruh pada peningkatan pendapatan petani kelapa dengan menjual sabutnya dan akan menciptakan lapangan pekerjaan bagi masyarakat serta akan mengurangi pengangguran dan akan meningkatkan nilai tambah pada produk, sehingga kebijakan-kebijakan untuk pengembangan agroindustri harus dilaksanakan dengan sebaik-baiknya.

2. Berdasarkan hasil penelitian maka dapat disimpulkan bahwa strategi yang tepat untuk pengembangan agroindustri sebutret di Kabupaten Sambas ada sembilan strategi yaitu: (1) Melakukan pendataan ulang tentang kepemilikan, fungsi dan tataguna lahan. (2) Melakukan studi kelayakan investasi usaha sebutret. (3) Memproduksi barang sebutret yang sesuai dengan citarasa konsumen dengan melakukan segmentasi pasar, targeting dan positioning. (4) Melakukan kegiatan persiapan sumber daya manusia, sumber daya alam, infrastruktur dan sumber pendanaan. (5) Membangun industri pengolahan sebutret yang berbasis kerakyatan. (6) Melakukan kerjasama dengan lembaga yang berkompeten dalam bidang pengolahan sebutret dalam proses alih teknologi dan penelitian lebih lanjut tentang proses pengolahan sebutret. (7) Menyediakan peralatan dan mesin proses produksi untuk menghasilkan produk sebutret. (8) Menyediakan tenaga ahli dibidang pengolahan sebutret dan bisnis agroindustri. Melakukan promosi produk sebutret. (9) Strategi yang telah disebutkan di atas merupakan hasil dari analisis pada faktor internal dan eksternal.

\section{Saran}

1. Diperlukan penelitian lebih lanjut lagi tentang teknologi proses pegolahan sebutret agar dapat menghasilkan produk yang lebih berkualitas dengan biaya produksi yang rendah sehingga harganya dapat bersaing dengan produk-produk sejenis yang berbahan baku dari sintetis, terjangkau oleh kalangan masyarakat 
menengah kebawah dan dapat diimplementasikan dalam industri yang berskala kecil atau berskala rumah tangga.

2. Diperlukan penelitian tentang penanggulangan berbagai resiko pertanian khususnya komoditas karet dan kelapa, seperti: resiko produksi yang disebabkan oleh iklim, hama dan penyakit dan bencana alam; resiko pasar dan pemasaran yang disebabkan oleh harga input dan output yang berfluktuasi; resiko manusia yang disebabkan adanya pencurian, kecelakaan dan tenaga kerja yang sakit; resiko institusional disebabkan oleh kebijakan-kebijakan yang dibuat oleh pemerintah dalam hal konsistensi dalam penerapan kebijakan; dan resiko keuangan/finansial yang disebabkan oleh permodalan, agar resiko-resiko yang menghambat untuk penyediaan bahan baku dalam pengembangan agroindustri sebutret dapat diminimalkan.

\section{DAFTAR PUSTAKA}

BPS Sambas. 2010. Sambas Dalam Angka. Pemda Sambas.

David FR. 2009. Manajemen Strategi (Konsep). Salemba Empat, Jakarta.

Hubeis M. 2011. Pemetaan Usaha Kecil Prospektif di Bogor. Program Magister

Mahzan S, Zaidi AMA, Arsat N, Hatta MNM, Ghazali MI, Mohideen SR. 2010. Study on Sound Absorbtion Properties of Coconut Coir Fibre ReinforcedComposite with Added Recycled Rubber. International Journal of Integrated Engineering Vol 2, No 1.http://penerbit.uthm.edu.my/ojs/index.php/ijie/article/view/126 [13Februari 2012].

Maspanger DR, Handoko B dan Haris U. 2001. Rekayasa Alsin Manufaktur Karet Busa Untuk Industri Pedesaan. Balai Besar Pengembangan Alat dan MesinPertanian Badan Penelitian dan Pengembangan Pertanian Departemen Pertanian. Jakarta.

Maspanger D, Sinurat M dan Drajat B. 2005. Mengenal Lebih Jauh Teknologi Pembuatan Barang Jadi Karet. Di dalam Warta Penelitian dan Pengembangan Pertanian Vol. 27 no.1. Bogor.

Pujiastuti L. 2007. Pengaruh Waktu dan Suhu Vulkanisasi pada Pembuatan Kasur dari Serat Sabut Kelapa Berkaret [Skripsi]. Bogor: Fakultas Teknologi Pertanian, Institut Pertanian Bogor.

Sinurat M. 2003. Teknologi Pembuatan Jok dari Serat Sabut Kelapa Berkaret. Di dalam Kursus Teknologi Barang Jadi Lateks 2003. Balai Penelitian Teknologi Karet. Bogor.

Tejano EA. 1985. State of the Art of Coconut Coir Dust and Husk Utilization (General Overview). Paper presented during the National Workshop on Waste Utilization, Coconut Husk held on November 12, 1984 at the Philippine Coconut Authority, Diliman, Quezon City, PHILIPPINES. (C) Philippine Journal of Coconut Studies.

Thulasirajan K dan Narasimha VL. 2011. Studies on Coir Fibre Reinforced Bituminous Concrete. International Journal of Earth Sciences and Engineering ISSN 0974-5904, Volume 04, No 06 SPL, October 2011, pp. 835-838. http://www.ace-klu.in/img/020410420.pdf [13 Februari 2012]. 